\title{
A Discourse Analysis of Arabic Research Articles in Islamic Studies
}

\author{
Sultan H. Alharbi \\ Department of English Language \& Translation, King Saud University, Riyadh, Saudi Arabia
}

Email address:

suhalharbi@ksu.edu.sa

\section{To cite this article:}

Sultan H. Alharbi. A Discourse Analysis of Arabic Research Articles in Islamic Studies. International Journal of Language and Linguistics. Vol. 4, No. 6, 2016, pp. 198-206. doi: 10.11648/j.ij11.20160406.12

Received: October 18, 2016; Accepted: October 27, 2016; Published: November 17, 2016

\begin{abstract}
This study explores the rhetorical organization of Arabic research article introductions (RAIs) in the field of Islamic studies applying Swales' [1, 2] Create-a-Research-Space (CARS) model of move/step analysis. A corpus of 20 RAIs, written by first-language Arabic speakers, was selected from the Journal of Islamic Studies. The findings showed that the fit between the CARS model, developed on the basis of RAIs in English, and the RAIs sampled in the current study only partial. That is, while there exist some differences between Arabic RAIs examined and what has been proposed in the CARS model in terms of the treatment of past research and the inclusion of some additional elements in the texts under consideration, there is a complete similarity regarding the degree of explicitness in outlining the purpose of the study and indicating the structure of RAs. Generally speaking, the findings obtained in the current study support those reported in other studies on RAIs in different languages other than English in that texts particularly from the soft disciplines are more likely to be affected by the cultural background of their authors. Limitations and the implications of the findings as well as recommending some suggestions for future research are provided.
\end{abstract}

Keywords: Genre Analysis, RAIs, Rhetorical Organisation, Arabic, Islamic Studies

\section{Introduction}

There has been recently a mounting interest in the study of Arabic written texts, and this area of research can be broadly classified into two sets of studies [see 3, for an overview]. The first set of studies has focused on the analysis of salient discourse and rhetorical features of Arabic written texts such as lexical repetition, structural parallelism, coordination, functions of connectives as well as some morpho-syntactic features [e.g., 4, 5-8]. Conducted within the framework of Contrastive Rhetoric [9-11], the second set of studies has sought to identify differences in textual organization and rhetorical strategies between Arabic and other languages (mostly English) [e.g., 12]. A more recent approach in exploring Arabic written texts has been the employment of a genre analysis/move analysis using Swales' CARS [1, 2] model to investigate Arabic RAIs from different disciplines [13-16]. This study can be considered as a continuation of these recent studies that have been carried out on Arabic RAIs and been using Swales' [1,2] genre analysis approach.

The main idea of Swale's genre analysis/move analysis $[1$,
2] is that a text within a genre generally follows a typical textual organisation, comprising a number of specific moves sequenced in a particular order which are also realized by a series of steps. Dudley-Evans and St John [17] explain moves and steps as follows:

A 'move' is a unit that relates to both the writer's purpose and to the content that $\mathrm{s} / \mathrm{he}$ wishes to communicate. A 'step' is a lower level text than the move that provides a detailed perspective on the options open to the writer in setting out the moves.

Swales' [1, 2] CARS model for RAIs are generally similar, consisting of three basic moves: establishing a territory (Move 1), establishing a niche (Move 2), and presenting the present study/occupying the niche (Move 3). Swales' CARS model allows for recycling of the moves particularly in lengthy RAIs [1]. These three moves are also realised by a number of steps as can be seen in Figure 1. According to the CARS model [1], RAIs often begin with Move 1 (establishing a territory) which establishes the general topic being discussed. This can be achieved by making centrality claims where the writer appeals to the readers to accept 
his/her research as part of a significant area of inquiry (Step 1 ), by making a topic generalization (Step 2), and/or by reviewing previous research (Step 3). Move 2 (establishing $a$ niche) requires the writer to show some limitations or incompleteness in the previous research by making a counterclaim (Step 1), identifying a gap in this research (Step 2),

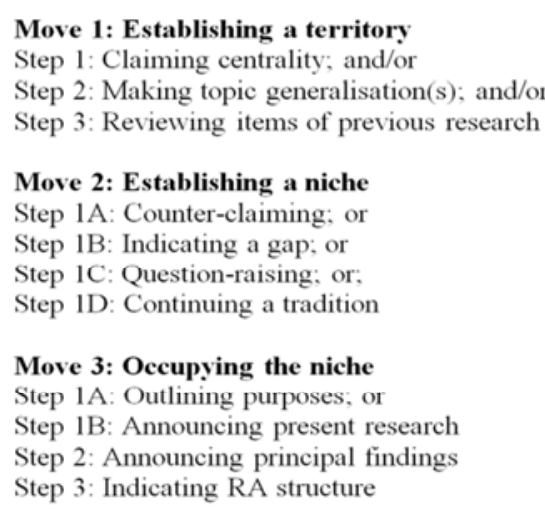

raising questions (Step 3). The writer can also builds on this research and extends it rather than challenging any part of this previous research (Step 4). Move 3 (occupying the niche) indicates the particular purpose of the research conducted (Step 1), announces the main findings (Step 2), or indicates the structure of the RA (Step 3).

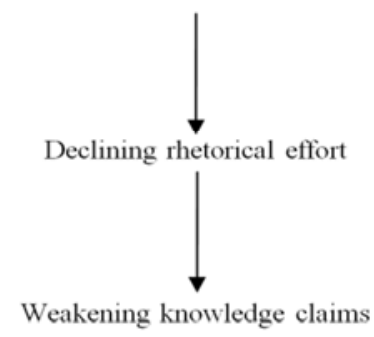

Figure 1. A CARS model for RAIs.
Swales' [1] CARS model was modified in 2004 based on the findings of the studies employing the model and reporting variations in RAIs [e.g., 18, 19]. Swales [2], for instance, collapsed Step 1 (claiming centrality) and Step 2 (making topic generalisations) of move 1 into one step: (topic generalisations of increasing specificity). While Swales reduced the three steps of Move 2: Step 1A (counterclaiming), Step 1B (indicating a gap), and Step 1C (questionraising) to one step: Step 1B (indicating a gap) in [2] modified CARS, he increased the number of steps in move 3 to seven in Swales' [2] modified CARS.

Two sets of studies were identified in the previous literature that utilised Swales' [1, 2] CARS framework in analysing the rhetorical organisation of RAIs. The first set is CARS studies in English which were carried out with the aim of exploring disciplinary variations [18-24]. These crossdisciplinary CARS studies on English RAIs have shown that academic discourse with regard to RAIs not only differs from one discipline to another $[18,19,21,22]$ but also subdisciplines within a particular discipline have their own preferences [23, 24]. The second set of studies is CARS cross-cultural/linguistic ones where different languages were examined and compared to English [e.g., 13, 15, 25-33]. Findings of these cross-cultural/linguistic studies on RAIs in different languages other than English have also revealed that these introductory secctions differ in their rhetorical organisation of RAIs in that, for instance, the employment of establishing a research gap (Move 2) either disappears completely or is employed with different strategies alien to the English RAI tradition. In short, these disciplinary and cross-cultural genre-based studies have indicated that Swales' $[1,2]$ CARS model is a valid and useful tool for analysing RAIs in English as well as in other languages. In addition, the findings of these studies have indicated that the genre of RAIs varies across languages, disciplines, and even within a single discipline.
The current study seeks to build upon the recent studies that employed Swale's genre analysis/move analysis $[1,2]$ on Arabic RAIs by exploring a new set of Arabic data from the field of Islamic studies. To the best of my knowledge, no literature has been reported which examine Arabic RAIs from this discipline. In their study on Islamic RAIs in English, Ahamad and Yusof [34] found that English RAIs from this field do not closely follow the move-pattern suggested by the CARS model, and that they contain a number of unique features (e.g., Quranic citation and reference to the Quran and Prophetic Sunnah) which are not found in the CARS model. Thus, the current study intends to determine the extent to which the Arabic RAIs from the field of Islamic studies are at variance with the predictions of the Swales CARS model.

The remainder of this article is divided into the following parts. Section (2) provides detailed information on the corpus and analytical procedure adopted for the current study. Section (3) presents the main findings and their discussion. Section (4) gives an overview of the study, describing its limitations and the implications of its findings as well as recommending some suggestions for future research

\section{The Corpus and Analytical Procedure}

\subsection{The Corpus}

The corpus used in the current study comprised 20 RAIs appearing in Journal of Islamic Studies (JIS), an academic periodical published in Saudi Arabia by King Saud University (see Appendix for the complete list of RAs). The selection of JIS was based on a consultation with two professors from the field of Islamic studies who revealed that $J I S$ journal is refereed and acknowledged by scholars for its reputation in the respective field. RAs in JIS examine issues related to topics such as the Prophetic Sunnah (i.e., Sunnah is one of the sources of Islamic legislation along with the 
Quran), Islamic culture, Islamic jurisprudence, Islamic Creed. Therefore, the RAs published in JIS are fairly representative of the Islamic RAs. Another reason for selecting RAs from this field is that these texts belong to soft disciplines, i.e., humanities and social sciences, which might show some interesting cultural/cross-linguistic aspects unlike hard disciplines, i.e., natural sciences [35]. The decision to focus on only RAs from this journal (JIS) was motivated by the fact that the conventional form and content of scholarly publications in a particular field of study are possibly to vary from journal to another $[26,36]$. Also, to control rapid changes within any of the disciplines, the 20 RAs chosen for the current study were written within a time span of three years (2012-2014). All RAs in the corpus are single-authored, and although the majority of the authors of these texts were from Saudi Arabia, there were also others from different Arab countries. The 20 RAs were analysed using the CARS model devised by Swales [1, 2].

\subsection{Analytical Procedure}

All the RAs in the corpus were structured into clearly labelled sections so that detecting the RAI was a relatively straightforward process. The analysis of the RAIs was conducted in several phases. First, the texts were analysed for some general features such as their overall organization. This was followed by a detailed examination of the RAIs employing the CARS model proposed by Swales $[1,2]$ in terms of moves and steps. The decision of employing Swales $[1,2]$ in the current study is due to the fact that this model has been used in many past studies, allowing for more insights based on comparison of findings whenever possible. It should also be noted that the detailed descriptions of the steps provided in the 1990 version will be drawn on when describing the realizations of Move 1 and Move 2 in Section (3.2.1) and Section (3.2.2) since the steps of these two moves in the 2004 version were short accounts of a number of steps. For instance, Step 1 in Move 1 in the [2] version (topic generalizations of increasing specificity) is a succinct account of Step 1 (claiming centrality) and Step 2 (making topic generalizations) in the 1990 version. The analysis was mainly qualitative but some quantification was employed to support observations. I re-analyzed $50 \%$ of the corpus five weeks after the original analysis without consulting the results of my first stage of analysis. The total percentage of agreements between the two analyses for all of RAIs examined exceeded $95 \%$ which is acceptable in qualitative research [e.g., 37, 38].

\section{Findings and Discussion}

This section presents the findings of the analysis of the RAIs in terms of their general organisation, the moves, and the steps used to realize the moves as well as providing some explanations for the main findings. It should be noted that extracts from the texts analysed with their translated versions into English will be included where appropriate.

\subsection{The General Organization of the Arabic RAIs from the Field of Islamic Studies}

Although the Arabic RAIs from the field of Islamic studies sampled in the current study contained some elements proposed by the CARS model (see Section 3.2), the texts also comprised some other components that are possibly to be viewed peculiar to those suggested by the model. That is, while all of the RAIs started off with the introductory religious statements, some RAIs $(60 \%)$ included acknowledgments and prayers at the end of RAI for some people who helped the writer in some way. Examples of these elements from the RAIs examined are provided in Extract (1) and Extract (2), respectively.

\section{Extract (1)}

$$
\text { تبعه بإحسان إلى بلى العالمبن، والصين... الصلاة والسلام على نبينا محمد وعلى آله وصحبه ومن }
$$

Praise be to Allah, and peace and blessings of Allah be upon Prophet Muhammad, his family and companions and those who righteously followed him until the Day of Judgement... (RA10)

\section{Extract (2)}

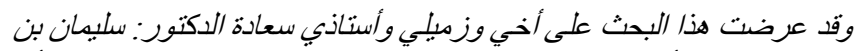

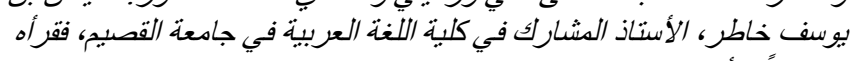

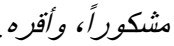

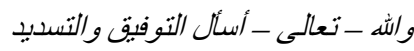

I presented this research paper to my brother, colleague, and teacher, Dr. Suleiman bin Yousuf Khater, the associate professor at the College of Arabic Language, Qaseem University, who read and approved it.

\section{I beg Allah, the Almighty, for complete success. (RA1)}

The employment of the opening religious statements, acknowledgements, and prayers as a part of the RAIs suggests that the Arabic RAIs from the field of Islamic studies do not reflect international conventions according to the norms of the English-speaking academic discourse community $[1,2]$. It therefore seems that the authors of these RAIs have a specific local target audience in their minds sharing with them the same disciplinary knowledge as well as the similar cultural background. Accordingly, the intended audience may expect the authors of the texts to use these elements in their RAIs. The inclusion of these components as a part of the RAIs might be ascribed to the fact that texts from soft disciplines, like the case in the current study, are better reveal the cultural aspects of writing as opposed to texts from hard disciplines [27]. Studies investigating Arabic RAIs from soft disciplines have reported the use of similar elements in the introductory sections of RAs from these fields of study [14]. Further studies are needed to identify whether Arabic RAIs from hard disciplines, e.g., physics, medicine, may feature similar rhetorical strategies.

According to the CARS model [1], authors of RAs need first to review past studies in the RAIs as a means to establish the areas of their research to readers (Move 1), to indicate some limitations in the earlier studies (Move 2), and then to 
specify how their studies occupy the niche that has been created (Move 3). However, it seems that the authors of the RAs investigated do not apply these tactics in any significant way. In other words, the majority of the RAIs under consideration do not use citations, and they also avoid any reference to specific studies both when establishing the territory as well as when creating the niche for their studies as can be seen in Extract (3) and Extract (4), respectively.

\section{Extract (3)}

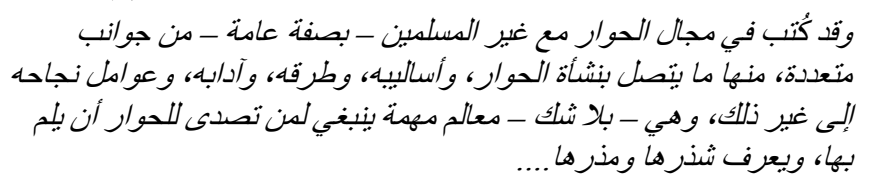

Research has been written in the field of dialogue with nonMuslims, in general, from different aspects. These aspects pertain to the origin of dialogue, its methods, means, ethics, and its success factors, ...etc. In fact, these are important landmarks, and those who are involved in dialogue should be fully aware of them... (RA8)

\section{Extract (4)}

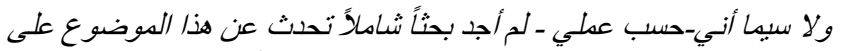

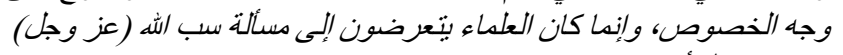
ضمن مسائل أخرى....

I have not found, to the best of my knowledge, a comprehensive research that dealt with this topic in particular; however, religious scholars discussed the issue of insulting Allah, the Almighty, among other things... (RA15)

The scarcity of citations of previous studies and the absence of critical evaluation of others' work in the texts confirm observations documented in other studies on RAIs in languages other than English [15, e.g., 16, 25, 26]. The discussion of the deficiency of significant consideration of previous scholarship and the lack of critical evaluation of others' work in the RAIs under consideration will be taken up again in Section 3.2.1 and Section 3.2.2, respectively.

Further, in order to establish the territories for their research and familiarize the readers with their topics, some of the RA authors make references to the Holy Quran and Prophetic Sunnah, and this essentially connected to stating the value of research as shown in Extract (5) and Extract (6).

\section{Extract (5)}

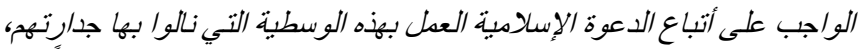

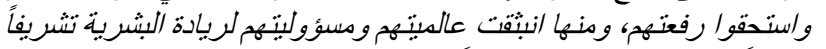

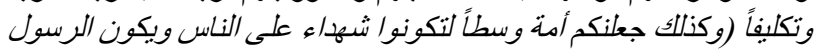
علبكم شهيدا).
The followers of Islamic Da'wa (call to Islam) should stick to moderation, by means of which they reached an elvated status, and from which emanated their responsibility of leading humanity. Allah, the Almighty, stated in the Holy Qur'an, "Thus, We have made you a Wasat (just) (and the best) nation, that you be witnesses over mankind and the Messenger (Muhammad) be a witness over you" (RA13)

\section{Extract (6)}

$$
\begin{aligned}
& \text { فتعد الأخلاق موضوعاً محورياً في منظومة التشريعات الإسلامية، وقضية }
\end{aligned}
$$

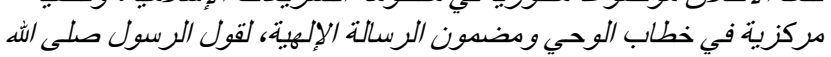

$$
\begin{aligned}
& \text { عليه وسلم (بعثت لأتمد مكارم الأخلاق). }
\end{aligned}
$$

Good manners are considered a pivotal subject in the Islamic legislation system as well as a central issue in the inspirational discourse and the essence of the Divine message. The Prophet (peace and blessings of Allah be upon him) said, "The only reason I have been sent is to perfect good manners" (RA5)

Reference to the Holy Quran and Prophetic Sunnah are two distinguishing features that can repeatedly be found in Islamic RAIs, and their employment in the RAIs analysed could however be viewed unrelated to the CARS model [1, 2]. The presence of these two features in the texts examined retains an important value being a major source of knowledge for Muslims. Thus, the occurrence of verses from the Holy Quran and sayings from the Prophetic Sunnah in the Islamic RAIs is considered as constantly pertinent and significant in texts from the field of Islamic studies whether in English [34] or in Arabic, as the case in the current study. This suggests the inclusion of some constituents in RAIs is experienced and valued differently by scholars publishing in different scientific communities (international and local)

\subsection{Move/Step Analysis}

This section will discuss the steps (S) that are used to realize the moves in the RAIs and the number of RAIs including them. While section 3.2.1 focuses on steps $(\mathrm{S})$ in Move 1, Section 3.2.2 and Section 3.2.3 deal with these steps (S) in Move 2 and Move 3, respectively.

\subsubsection{Move 1}

The role of Move 1 is to establish a territory for the study to be presented through one or more of three possible steps: M1-S1 (claiming centrality), M1-S2 (making topic generalizations), and M1-S3: (reviewing items of previous

\begin{tabular}{|c|c|c|c|c|c|c|c|c|c|c|c|c|c|c|c|c|c|c|c|c|}
\hline RA & 1 & 2 & 3 & 4 & 5 & 6 & 7 & 8 & 9 & 10 & 11 & 12 & 13 & 14 & 15 & 16 & 17 & 18 & 19 & 20 \\
\hline M1-S1 & 1 & 1 & 1 & 3 & 1 & 2 & & 1 & 2 & 1 & 1 & 2 & 3 & 2 & 1 & 1 & & 1 & 2 & 1 \\
\hline M1-S2 & & 1 & 1 & 1 & & & 1 & & 1 & 1 & 1 & & 1 & & & & 1 & 1 & & \\
\hline M1-S3 & & & 2 & & 1 & & & & & & & & & & 1 & 1 & 1 & & & 1 \\
\hline
\end{tabular}
research). While Table 1 indicates the number of the instances of the three steps in each RAI in the corpus, Table 2 shows the distribution of these steps in Move 1.

Table 1. Number of instances of steps in Move 2 in each RAI. 
Table 2. Distribution of steps in Move 1.

\begin{tabular}{lll}
\hline Steps (S) & Number of instances & Number of RAs \\
\hline M1-S1: (claiming centrality) & 27 & 18 \\
M1-S2: (making topic generalizations) & 10 & 10 \\
M1-S3: (reviewing items of previous research) & 7 & 6 \\
\hline
\end{tabular}

As can be seen in Table 2, the most frequent step within Move 1 in the Arabic RAIs from the field of Islamic studies is M1-S1 (centrality claims). This step was used to realize Move 1 in 18 RAIs with 27 instances. The authors of RAIs sampled in the current study signalled their intention to claim the centrality of their own topics by employing positive connotations associated with importance or interest such as in these examples in Extract (7) and Extract (8).

\section{Extract (7)}

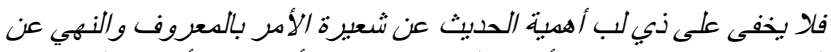

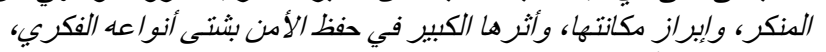

$$
\begin{aligned}
& \text { والسياسي، والأخلافي، والاجتماعي، والنراكي، والنفسي، والاقتصادي... }
\end{aligned}
$$

No sensible person will fail to detect the importance of talking about the rite of promoting virtue and preventing vice, and its great impact on preserving intellectual, political, moral, social, psychological and economic security. (RA6)

\section{Extract (8)}

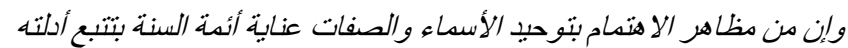

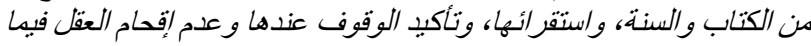

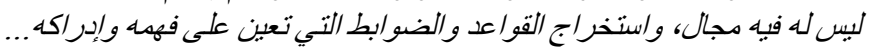
The imams of Sunnah paid attention to monotheism in terms of the Names and Attributes of Allah. They followed the evidence of monotheism in the Qur'an and Sunnah, inferred its meanings, and stressed the necessity of abiding by them and not going beyond them. They also highlighted the rules and regulations that help Muslims understand true monotheism... (RA1)

The analysis of the data shows M1-S1 (centrality claims) was found to be the most common step of Move 1 (i.e., establishing a territory) in the texts under consideration. Similar findings were also observed in Arabic RAIs in other fields [14, education, 16, law] in that Arab RA authors tended to frequently employed centrality claims as a means to establish the territory of their topics. Cross cultural studies employing Swales' CARS model on RAIs in different languages other than English have indicated that while authors in some culture avoid using centrality claims in the RAIs as such a step would be considered assertive and unacceptable [29], in some other cultures, authors used centrality claims as a strategy to help establish the territory [36]. The higher frequency of topic importance claims in the RAIs examined is inconsistent with the finding of Ahamad and Yusof [34], who found that M1-S2 (making topic generalizations) is the most preferable step to actualize Move 1 in Islamic RAIs in English. It seems that the reason for the greater occurrence of centrality claims in Arabic RAIs from the field of Islamic studies could not be attributed to the disciplinary nature of the field of Islamic studies but to the cultural background of the authors, i.e., Arabic. Accordingly, this suggests that written academic texts are shaped by not only disciplinary norms but also by other factors including the cultural background of their authors, as the case in the current study.

As can been seen in Table 2, reviewing of past research (i.e., M1-S3) in the Arabic RAIs from the field of Islamic studies was found to appear only in half of the texts analyzed, and when used, only offering limited discussion of previous research (see Section 3.2). Similar observations have been documented in other studies on RAIs in languages other than English [e.g., 26], and the discussion of the absence of significant consideration of previous scholarship in the RAIs under consideration of will be discussed in Section (3.2.2).

\subsubsection{Move 2}

The general function of Move 2 is to present a rationale for conducting the reported study through one or more of four possible steps: M2-S1 (Counter-claiming), M2-S2 (Indicating a gap), M2-S3 (Questing-raising), and M2-S4 (Continuing a tradition). While Table 3 shows the number of the instances of the four steps in each RAI in the corpus, Table 4 indicates the distribution of these steps in Move 2.

Table 3. Number of instances of steps in Move 2 in each RAI.

\begin{tabular}{lllllllllllllllllllll}
\hline RA & $\mathbf{1}$ & $\mathbf{2}$ & $\mathbf{3}$ & $\mathbf{4}$ & $\mathbf{5}$ & $\mathbf{6}$ & $\mathbf{7}$ & $\mathbf{8}$ & $\mathbf{9}$ & $\mathbf{1 0}$ & $\mathbf{1 1}$ & $\mathbf{1 2}$ & $\mathbf{1 3}$ & $\mathbf{1 4}$ & $\mathbf{1 5}$ & $\mathbf{1 6}$ & $\mathbf{1 7}$ & $\mathbf{1 8}$ & $\mathbf{1 9}$ & $\mathbf{2 0}$ \\
\hline M2-S1 & & & & & & & & & & & & & & & & & 1 & & \\
M2-S2 & & & & & 1 & 2 & & & & 2 & & & & 1 & 1 & 2 & & 1 & 1 & 1 \\
M2-S3 & 1 & & & & & & & & & & & & & & & & & & &
\end{tabular}

Table 4. Distribution of steps in Move 2.

\begin{tabular}{lll}
\hline Steps (S) & $\begin{array}{l}\text { Number of } \\
\text { instances }\end{array}$ & $\begin{array}{l}\text { Number of } \\
\text { RAs }\end{array}$ \\
\hline M2-S1: (Counter-claiming) & 1 & 1 \\
M2-S2: (Indicating a gap) & 12 & 9 \\
M2-S3: (Questing-raising) & 1 & 1 \\
M2-S4: (Continuing a tradition) & 1 & 1 \\
\hline
\end{tabular}

As can be seen from Table 3, eight out of 20 RAIs lack Move 2 (i.e., they do not establish a niche). Also, none of the texts employing Move 2 have adopted the strategies proposed in the CARS model in any meaningful way. That is, they simply summarized the work of others, avoiding criticizing or challenging the cited works as a stragety of establishing a 
niche, as proposed by the CARS model $[1,2]$ as can be found in Extract (2). It thus appears that Move 2 (i.e., establishing a niche) is not a vital constituent of the Arabic RAIs from the area of the Islamic studies, and that the general norm in these texts is the absence of an explicit critical stance to highlight the shortcomings of earlier works. This finding suggests that Arab writers from the field of Islamic studies do not place as much emphasis on specifying the gaps of earlier studies, tending to omit Move 2. This finding further supports past studies which showed establishing the niche that is not predominant in RAIs written in languages other than English, such as Arabic [13-15], Chinese [25, 26], Malay [28], and Thai. [29].

A few potential explanations accounting for the avoidance of specific reference to earlier works in the RAIs to create a niche for one's research (i.e., the omission of Move 2) have been offered in the literature [e.g., 13, 15, 16, 29]. The most relevant of these explanations to the present situation is the one proposed by Fakhri [16] which "is based on crosscultural [cross-disciplinary variation regarding attitudes toward the creation and transmission of knowledge". Bereiter and Scardmalia [39] describe knowledge telling is the process in which writers simply employ the knowledge readily available to them mainly gained through reading or instruction. On the other hand, knowledge transforming is a more complex process, of which knowledge telling is one part. In this knowledge-transforming model, writers go beyond knowledge-telling to rework and transform their knowledge which demands critical evaluation of formerly acquired knowledge with the aim of increasing it through creation of new knowledge. The primary source for knowledge of the discipline of the Islamic studies are obtained from religious texts, particularly the Holy Quran and the Prophet's sayings. These two sources for knowledge are considered as high reverence according to inherited knowledge in this discourse community. Thus, it seems that writers from the field of Islamic studies are only required to memorise this knowledge and transmit it without little change or innovation since that mere knowledge-telling is regarded by members of this discourse community as scholarship worthy of publication [cf. 40].

Also, it should be mentioned here that the finding that the authors of the texts analyzed in the current study showed preference to the step M2-S2 (indicating a gap) is partially consists with that of Ahamad and Yusof [34] who found that the author of Islamic RAIs in English prefer to use the same step within Move 2, i.e., indicating a gap. However, it is worth noting here that the employment of the M2-S2 (indicating a gap) in texts under consideration, as stated in Section 3.1, was not done as proposed by the CARS model since the findings of previous works were taken for granted and were supplied to familiarize the reader with the topic.

\subsubsection{Move 3}

Move 3 is the move where the niche described in Move 2 is occupied. This is done by one or more of seven possible steps: M3-S1 (outlining purposes, or announcing present research), M3-S2 (announcing principal findings), M3-S3 (indicating RA structure), M3-S4 (presenting RQs or hypotheses), M3-S5 (definitional clarifications), M3-S6 (summarizing methods), and M3-S7 (stating the value of the present research). While Table 5 shows the number of the instances of the seven steps in each RAI, Table 6 indicates the distribution of these steps in Move 3.

Table 5. Number of instances of steps in Move 3 in each RAI.

\begin{tabular}{|c|c|c|c|c|c|c|c|c|c|c|c|c|c|c|c|c|c|c|c|c|}
\hline RA & 1 & 2 & 3 & 4 & 5 & 6 & 7 & 8 & 9 & 10 & 11 & 12 & 13 & 14 & 15 & 16 & 17 & 18 & 19 & 20 \\
\hline $\begin{array}{l}\text { M3-S1 } \\
\text { M3-S2 }\end{array}$ & 1 & 1 & 3 & 2 & 2 & 2 & 2 & 1 & 1 & 3 & 1 & 1 & 1 & 2 & 2 & 2 & 1 & 3 & 2 & 2 \\
\hline $\begin{array}{l}\text { M3-S3 } \\
\text { M3-S4 } \\
\text { M3-S5 }\end{array}$ & 1 & 1 & 1 & 1 & $\begin{array}{l}1 \\
1 \\
1\end{array}$ & $\begin{array}{l}1 \\
1\end{array}$ & 1 & 1 & 1 & $\begin{array}{l}1 \\
2\end{array}$ & 1 & 1 & 1 & 1 & 1 & 1 & 1 & $\begin{array}{l}1 \\
1\end{array}$ & $\begin{array}{l}1 \\
1\end{array}$ & 1 \\
\hline $\begin{array}{l}\text { M3-S6 } \\
\text { M3-S7 }\end{array}$ & & & $\begin{array}{l}1 \\
1\end{array}$ & 1 & $\begin{array}{l}1 \\
2\end{array}$ & $\begin{array}{l}1 \\
1\end{array}$ & 2 & 1 & $\begin{array}{l}1 \\
1\end{array}$ & 1 & & 1 & 1 & & & $\begin{array}{l}1 \\
1\end{array}$ & & & 1 & $\begin{array}{l}1 \\
1\end{array}$ \\
\hline
\end{tabular}

Table 6. Distribution of steps in Move 3.

\begin{tabular}{lll}
\hline Steps (S) & Number of instances \\
\hline M3-S1: (outlining purposes, or announcing present research) & 35 \\
M3-S2: (announcing principal findings) & 0 \\
M3-S3: (indicating RA structure) & 20 \\
M3-S4: (presenting RQs or hypotheses) & 6 \\
M3-S5: (definitional clarifications) & 1 \\
M3-S6: (summarizing methods) & 11 \\
M3-S7: (stating the value of the present research) & 10 \\
\hline
\end{tabular}

The analysis of the data shows that the most commonly used steps of Move 3 are M3-S1 and M3-S3 in that these two were used all the RAIs under consideration as shown in Extract (9) and Extract (10), respectively.

\section{Extract (9)}

$$
\text { ولهذا كله أحببت أن أجدع بحثاً مشتملاً على بيان حكم سب الرحمن، وصور }
$$

$$
\text { .....السب، وحكم الجلوس مع السابين، والاستصاع إليهم }
$$

Therefore, I gathered a research that included the judgment on insulting Allah, forms of insult as well as the judgment on sitting with those who insult Allah and listening to them... (RA 15) 


\section{Extract (10)}

$$
\text { قد قسّمت البحث إلى: مقامة، وفصلين، وخاتمة، وفعهارس. فالفصل الأول عن }
$$$$
\text { مصير أطفال الدسلمين في الآخرة.... }
$$

I divided the research into an introduction, two chapters, a conclusion, and bibliography. The first chapter deals with the fate of Muslim children in the Hereafter... (RA 18)

It is not surprising that M1-S1 (i.e., outlining purposes, or announcing present research) is present in the RAIs examined since this step is obligatory and required in all RAIs according to the CARS model $[1,2]$. This finding corroborates those reported in past studies which found that this step is commonly present in most of RAIs studied [e.g., 26]. Further, the presence of M3-S3 (indicating RA structure) in the texts analyzed suggests this step is an essential element of RAIs from the field of Islamic studies because according to the CARS model $[1,2]$, M3-S3 is a discipline-specific. However, the finding that all of the RAIs examined in the current study explicitly stated the structure of the RA is inconsistent with that of Fakhri $[13,16]$. Fakhri found that not all Arabic RAIs from the humanities utilized this step. It seems that the authors of the RAIs sampled in the current study employed the indication of the structure of RAs as metadiscourse device to orient and guide their readership in order to help them understand text message without difficulty. It is worth mentioning here that this finding also gives supports to Fakhri [13] who claimed that it could be imprecise to categorize Arabic writing as reader-responsible or writer-responsible [41] since the "dichotomies of directindirect styles and reader responsible versus writerresponsible rhetoric are too general and probably too simplistic" [13]. In other words, while explicitly declaring the purpose of the study and stating the structure of the RA, all of Arabic RAIs analyzed exhibited a high degree of directness and explicitness similar to English RAs [1,2]. The lesser employement of some of the steps in Move 3 in the texts under consideration may be due to the fact that the step is either optional (e.g., M3-S5) or probable in some fields but unlikely in others. (e.g., M3-S2) [2].

\section{Conclusion}

The current study was designed to investigate the rhetorical organization of Arabic RAIs from the field of Islamic studies, employing Swales' [1,2] CARS model as an analytical framework. The findings of the current study give support to those in other studies on RAIs showing that the CARS model is a valid and useful tool for analysing the RAIs not only in English [e.g., 18, 19, 21, 23], but also in other languages, even if researchers of RAIs in languages other than English have been obliged to modify the CARS model somewhat to take account of the intervening roles of some linguistic and cultural parameters. Hence, the model could be employed with careful application [27] in the investigation of other Arabic RAIs from different areas of study; however, this remains to be examined in future research.
The findings showed that the fit between the CARS model, developed on the basis of RAIs in English, and the RAIs sampled in the current study only partial. In other words, while there exist some differences between Arabic RAIs from the field of Islamic studies and what has been proposed in the CARS model in terms of the treatment of past research and the inclusion of some additional elements in the texts under consideration, there is a complete similarity regarding the degree of explicitness in outlining the purpose of the study and indicating the structure of RAs in that all the Arabic RAIs from the discipline of the Islamic studies employed these two devices. Overall, the findings obtained in the current study support those reported in other studies on RAIs in different languages other than English in that texts particularly from the soft disciplines are more likely to be affected by the cultural background of their authors [e.g., 32]. This exploratory study investigated a small corpus of Arabic RAIs from the field of Islamic studies, and the findings reported here only reflect the rhetorical organization identified in this particular corpus. Larger studies investigating more Arabic RAIs published in Arab countries are necessary to verify whether the findings obtained in this study can be generalized. The findings of this study raise the writer's awareness regarding disciplinary variation as an important aspect in academic disocurse which helps in understanding the 'culture' of writing and getting familiar with the conventions and expectations of a specific disciplinary community.

\section{Acknowledgment}

The author expresses his appreciation to the Deanship of Scientific Research at King Saud University, Saudi Arabia, and the Research Center at the College of Languages \& Translation for offering support for the current article.

\section{Appendix}

(RA1): Al-Dobikhy, Suoliman, 2012. Transitive and intransitive verbs in relation to Allah's acts from religious and grammatical perspective. Journal of Islamic Studies 25, 59-74.

(RA2): Al-Afandy, Said, 2012. Spiritism: Definition, evolution, ways, and criticism. Journal of Islamic Studies 25, 75-100.

(RA3): Ahadjahjh, Jaber, 2012. Repentance implications for wavering punishments: A comparative study. Journal of Islamic Studies 25, 101-126.

(RA4): Al-Nasser, Abdullah, 2012. Shar'i politics in the Prophet's acts. Journal of Islamic Studies 25, 167-200.

(RA5): Khatatbha, Adnan, 2012. Foundations of ethical education of the Muslims preacher in relation to contemporary reality. Journal of Islamic Studies 25, 201-239.

(RA6): Al-Saif, Sultan, 2012. Deserting the practice of the promotion of virtue and the prevention of vice: Causes and remedies in the light of the Quran and the Sunnah. Journal of Islamic Studies 25, 241-272. 
(RA7): Alshinqitee, Assalem, 2013. Technical classification of the Quran Qurra: Qari, Rawi, and Tariq. Journal of Islamic Studies 25 (2), 45-71.

(RA8): Al-Ahmad, Ali, 2013. Debating with Christians: Scopes, aims, and requirements. Journal of Islamic Studies 25 (2), 73-117.

(RA9): Shouha, Khalid, Childhood rights: Dealing with their problems in the light of the Quran. Journal of Islamic Studies 25 (2), 119-143.

(RA10): Yemeni, Mohammed, 2013. Salam Suku: A comparative jurisprudence study. Journal of Islamic Studies 25 (2), 145-176.

(RA11): Al-Shunyber, Khalid, 2013. War in Judaism: Exposition and critique. Journal of Islamic Studies 25 (2), 229-263.

(RA12): Al-Sawalmeh, Abdullah, 2013. Ibn-Omar's Hadith on the divorce of menstruating women. Journal of Islamic Studies 25 (3), 47-83.

(RA13): Neyas, Rugaia, 2013. Caller's motives for Wassatiyyah in approach and aim. Journal of Islamic Studies 25 (3), 85-113.

(RA14): Al-Suqair, Sami, 2013. Excuses for not standing in obligatory prayers. Journal of Islamic Studies 25 (3), 115152.

(RA15): Al-Hushani, Maryam, 2013. Explaining the offence of Cursing Allah. Journal of Islamic Studies 25 (3), 153-180.

(RA16): Al-Tubeshi, Sultan, 2013. Identifying the Awzaa'iy companions. Journal of Islamic Studies 25 (3), 181-215.

(RA17): Al-Amer, Fahad, 2014. An analytical inductive study on the use of gesture in Al-Jarhwa Al-Tadil (Discrediting and Accrediting Hadith Narrators). Journal of Islamic Studies 26 (1), 191-243.

(RA18): Al-Romain, Abdullah, 2014. The fate of children in the Hereafter. Journal of Islamic Studies 26 (1), 245-271.

(RA19): Al-Missned, Mohammed, 2014. Concealment in Surat Al-Baqarah: Forms and Consequences. Journal of Islamic Studies 26 (1), 273-297.

(RA20): Altayyar, Musaed, 2014. Enhancing Quranic sciences through Sahih Al-Bukari's Book of Interpretation: Specific application to Surat Al-Fatihah. Journal of Islamic Studies 26 (1), 17-44.

\section{References}

[1] Swales, J. M., Genre analysis: English in academic and research settings. Cambridge applied linguistics series 1990, Cambridge, UK: Cambridge University Press. xi, 260 p.

[2] Swales, J. M., Research genres: Explorations and applications. Cambridge applied linguistics series 2004, Cambridge, UK: Cambridge University Press. xii, 314 p.

[3] Fakhri, A., Discourse analysis, in Encyclopedia of Arabic Language and Linguistics 1, K. Versteegh, Editor 2005, Brill Academic Publishers: Leiden, Netherlands. p. 364-365.

[4] Al-Jubouri, A., The role of repetition in Arabic argumentative discourse, in English for Specific Purposes in the Arab World, J. M. Swales and H. Mustapha, Editors. 1984, University of Aston: Birmingham, UK. p. 99-117.

[5] Johnstone, B., Repetition in Arabic discourse. 1991, Amsterdam, Netherlands: John Benjamins.

[6] Al-Batal, M., Connectives as cohesive elements in a modern expository Arabic text, in Perspectives on Arabic Linguistics II, M. Eid and J. McCarthy, Editors. 1990, John Benjamins: Amsterdam, Netherlands. p. 234-268.

[7] Johnstone, B., Orality and discourse structure in Modern Standard Arabic, in Perspectives on Arabic Linguistics I, M. Eid, Editor. 1990, John Benjamins: Amsterdam, Netherlands. p. $215-233$.

[8] Fakhri, A., Topic continuity in Arabic narrative discourse, in Perspectives on Arabic Linguistics VII, M. Eid, Editor. 1995, John Benjamins: Amsterdam, Netherlands. p. 141-155.

[9] Kaplan, R. B., Cultural thought patterns in intercultural education. Language learning, 1966. 16 (1-2): p. 1-20.

[10] Connor, U., Contrastive Rhetoric: Cross-cultural aspects of second-language writing. 1996, Cambridge, UK: Cambridge University Press.

[11] Connor, U., Contrastive rhetoric: Old and new directions, in Contrastive rhetoric: Issues, insights, and pedagogy, $\mathrm{N}$. Kassabgy, Z. Ibrahim, and S. Aydelott, Editors. 2004, American University in Cairo Press: Cairo, Egypt. p. 1-23.

[12] Fakhri, A., Topical structure in Arabic English interlanguage, in Pragmatics and Language Learning, L. Bouton, Editor. 1995, University of Illinois, Urbana-Champaign: IL, US. p. $155-168$.

[13] Fakhri, A., Rhetorical properties of Arabic research article introductions. Journal of Pragmatics, 2004. 36 (6): p. 11191138 .

[14] Al-Qahtani, A. A., A contrastive rhetoric study of Arabic and English research article introductions, 2006, Oklahoma State University: OK, US.

[15] Najjar, H., Arabic as a research language: The case of agricultural sciences, 1990, University of Michigan: Ann Arbor, Michigan.

[16] Fakhri, A., Rhetorical variation in Arabic academic discourse: Humanities versus law. Journal of Pragmatics, 2009. 41 (2): p. 306-324.

[17] Dudley-Evans, T. and M. J. St John, Developments in English for specific purposes. A multi-disciplinary approach. 1998, Cambridge, UK: Cambridge University Press.

[18] Samraj, B., Introductions in research articles: Variations across disciplines. English for Specific Purposes, 2002. 21 (1): p. 1-17.

[19] Anthony, L., Writing research article introductions in software engineering: How accurate is a standard model? IEEE Transactions on Professional Communication, 1999. 42 (1): p. 38-46.

[20] Samraj, B., A discourse analysis of master's theses across disciplines with a focus on introductions. Journal of English for Academic Purposes, 2008. 7 (1): p. 55-67. 
[21] Samraj, B., An exploration of a genre set: Research article abstracts and introductions in two disciplines. English for Specific Purposes, 2005. 24 (2): p. 141-156.

[22] Samraj, B., Discourse features of the student-produced academic research paper: Variations across disciplinary courses. Journal of English for Academic Purposes, 2004. 3 (1): p. 5-22.

[23] Ozturk, I., The textual organisation of research article introductions in applied linguistics: Variability within a single discipline. English for Specific Purposes, 2007. 26 (1): p. 2538 .

[24] Kanoksilapatham, B., Distinguishing textual features characterizing structural variation in research articles across three engineering sub-discipline corpora. English for Specific Purposes, 2015. 37: p. 74-86.

[25] Taylor, G. and C. Tingguang, Linguistic, cultural, and subcultural issues in contrastive discoure analysis: AngloAmerican and Chinese scientific texts. Applied Linguistics, 1991. 12 (3): p. 319-336.

[26] Loi, C. K., Research article introductions in Chinese and English: A comparative genre-based study. Journal of English for Academic Purposes, 2010.9 (4): p. 267-279.

[27] Duszak, A., Academic discourse and intellectual styles. Journal of Pragmatics, 1994. 21 (3): p. 291-313.

[28] Ahmad, U., Research article introductions in Malay: Rhetoric in an emerging research community, in Culture and styles of academic discourse, A. Duszak, Editor. 1997, Mouton de Gruyter: Berlin, Germany. p. 273-303.

[29] Jogthong, C., Research article introductions in Thai: Genre analysis of academic writing, 2001, West Virginia University: Morgantown, West Virginia.

[30] Árvay, A. and G. Tankó, A contrastive analysis of English and Hungarian theoretical research article introductions. International Review of Applied Linguistics in Language Teaching, 2004. 42 (1): p. 71-100.

[31] Hirano, E., Research article introductions in English for specific purposes: A comparison between Brazilian Portuguese and English. English for Specific Purposes, 2009. 28 (4): p. $240-250$.
[32] Sheldon, E., Rhetorical differences in RA introductions written by English L1 and L2 and Castilian Spanish L1 writers. Journal of English for Academic Purposes, 2011. 10 (4): p. $238-251$.

[33] Lee, S., Contrastive rhetorical study on Korean and English research paper introductions. Journal of Pan-Pacific Association of Applied Linguistics, 2000. 4 (2): p. 316-36.

[34] Ahamad, M. I. and A. M. Yusof, A Genre analysis of Islamic academic research article introductions. Procedia - Social and Behavioral Sciences, 2012. 66: p. 157-168.

[35] Becher, T. and R. P. Trowler, Academic tribes and territories: Intellectual enquiry and the culture of disciplines. 2nd ed 2001, Buckingham, UK: The Society for Research into Higher Education \& Open University Press. xv, 238 p.

[36] Shim, E., Explicit writing instruction in higher education context: Genre analysis of research article introductions from the English Teaching and the TESOL Quarterly Journals., 2005, The University of Minnesota: MN, US.

[37] Mackey, A. and S. M. Gass, Second language research: Methodology and design. 2005, Mahwah, NJ: Lawrence Erlbaum Associates.

[38] Miles, M. B. and A. M. Huberman, Qualitative data analysis: An expanded sourcebook. 2nd ed 1994, Thousand Oaks, CA: Sage.

[39] Bereiter, C. and M. Scardmalia, The psychology of written composition. 1987, Hillsdale, NJ: Lawrence Erlbaum Associates.

[40] Bloch, J. and L. Chi, A comparison of the use of citations in Chinese and English academic discourse., in Academic writing in a second langauage: Essays on research and pedagogy, D. Belcher and G. Braine, Editors. 1995, Ablex: Norwood, NJ. p. 231-273.

[41] Hinds, J., Reader versus writer responsibility: A new typology, in Writing across languages: Analysis of L2 text, U. Connor and R. B. Kaplan, Editors. 1987, Addison-Wesley: Reading, MA. p. 141-152. 